\title{
THE JUGULAR VENOUS PULSE
}

\author{
By D. S. SHORT, M.D., M.R.C.P.* \\ The Institute of Clinical Research and Experimental Medicine, the \\ Middlesex Hospital, and the Cardiac Department, the London Hospital
}

\begin{abstract}
"Study of the veins still suffers an unfortunate neglect; in these vessels are to be found some of the most valuable signs we possess in managing heart cases."-Sir Thomas Lewis, 1948.
\end{abstract}

Although the neglect of which Sir Thomas Lewis spoke has since been partially remedied, there is no doubt that the value of the jugular pulse is still insufficiently realized. Important information can be obtained both from the form of the venous pulse and the level of venous distension by simple observation without the aid of any instrument.

This paper is based on a careful inspection of the jugular pulse in over 3,000 patients with congenital or acquired heart disease aged between five and 80 years and 100 healthy men aged between 20 and 60 years.

Until recently clinical interest has been focused exclusively on either the wave form or the venous pressure. It is only in the past decade, due largely to the observations of Wood (1950, 1956), that both have found their proper recognition.

Venous pulsation was occasionally recorded in the 18 th century, notably by Lancisi ( 1728$)$, but no important contribution to the subject was made until the introduction of sphygmography, which permitted the taking of actual tracings (Friedreich, I866; Potain, 1867). Mackenzie (1893) recorded the jugular and arterial pulses simultaneously and made a systematic analysis of the clinical significance of the venous pulse. He recognized the waves and designated them in accordance with the events in the cardiac cycle, which he believed they reflected. At first the chief clinical application of the venous pulse lay in the diagnosis of arrhythmias, but in this it was soon to be superseded by the electrocardiogram. Interest in the venous waves then waned until the advent of cardiac catheterization and cardiac surgery led to more precise diagnosis of congenital heart disease and a consequent reappraisal of physical signs (Wood, I950).

In 1733 Hales measured the jugular venous pressure in a mare by inserting a glass tube into the vein. This procedure cannot readily be applied to

* Holding a Leverhulme Scholarship. man, but Moritz and Tabora (19ro) showed that the venous pressure could be recorded by inserting a needle into the median cubital vein and attaching it to a manometer filled with sodium citrate. This method has been widely used in the past, but it is too complicated for routine use; it measures the peripheral rather than the central venous pressure and an equally accurate estimate can be obtained much more simply. Lewis (1930) showed that the jugular veins could be regarded as natural manometers connected to the right atrium, and that the central venous pressure could be determined by observing the height of the venous column above the sternal angle.

\section{The Anatomy of the Jugular Veins}

There are three main veins running downwards on each side of the neck: the external, the anterior and the internal jugular veins (Fig. I).

The external and anterior jugular veins are covered only by skin, superficial fascia and the thin platysma muscle, so that when distended they are visible throughout most of their course. The external jugular vein runs from the angle of the mandible to the middle of the clavicle, where it enters the subclavian vein. Its size varies in inverse proportion to the other veins of the neck. The anterior jugular vein begins near the hyoid bone, runs downwards between the anterior border of the sternomastoid and the midline, and turns laterally in the lower part of the neck to enter the external jugular or the subclavian vein. The two anterior jugular veins are united just above the sternum by a transverse trunk called the jugular arch.

The internal jugular vein lies within the carotid sheath, deep to the sternomastoid muscle. It runs from the jugular foramen of the skull to a point behind the sternal end of the clavicle, where it unites with the subclavian vein to form the innominate vein. Near its termination it dilates to form the inferior jugular bulb.

The external jugular vein has two pairs of valves, both of which are incompetent; an upper pair situated about $4 \mathrm{~cm}$. above the clavicle, and a lower pair immediately above its termination. The 


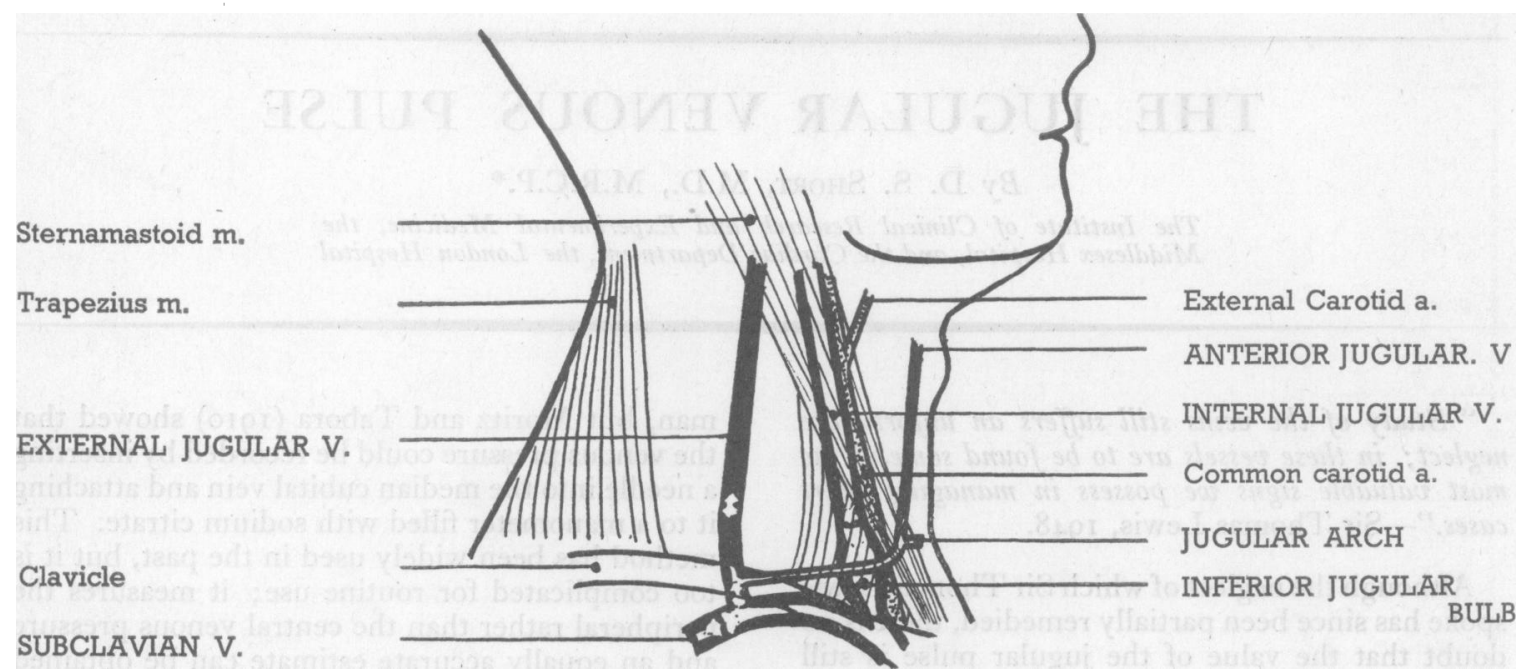

Fig. 1.-The anatomy of the jugular veins. Note the position of the valves in the external jugular, internal jugular, and subclavian veins. Those in the external jugular vein are incompetent. Veins running superficially are shown in solid black.

anterior jugular vein has no valves. The internal jugular vein has a pair of valves immediately above its inferior bulb. The only valves in the subclavian vein lie on the lateral side of the external jugular opening. There are no valves in the innominate veins or in the superior vena cava. Thus there are no competent valves between the right atrium and the upper ends of the external and anterior jugular veins, or between the heart and the inferior jugular bulb. The internal jugular valves readily become incompetent in the presence of a raised right atrial pressure.

Keith (1908) believed that during atrial contraction the openings of the caval veins became occluded by a band of muscle fibres. The experimental evidence is, however, wholly against this view (Wiggers, 1928). The pressure curve recorded from a cannula in the superior vena cava corresponds to that recorded in the right atrium itself, and this still holds true when all the tributaries of the superior vena cava are ligated.

\section{The Normal Jugular Venous Pulse}

Pulsation in the superficial jugular veins is a normal phenomenon, and so is pulsation over the inferior jugular bulb. Observations of pressure are best made in the external jugular vein. The venous waves, on the other hand, are most accurately reproduced in the internal jugular vein, which is in direct line with the right atrium. In the external jugular vein the undulations, although visible, are somewhat delayed and flattened.

In order to observe the jugular pulse, the patient should lie almost flat, and be completely relaxed. If no pulsation can be seen, this is prob- ably because the top of the column of blood is too low and lies within the chest, or too high and lies within the head (Fig. 2). Veins that are fully distended cannot pulsate appreciably, neither can those that are collapsed. The next step, therefore, is to place a finger lightly over the lower end of the external jugular vein and wait $\mathrm{I}_{5}$ seconds to see if the vein fills. If it does not, the same procedure should be applied to the anterior jugular vein. If either vein fills, it indicates that the venous pressure is too low to be recorded with the patient in his present position and the jugular pulse may be assumed to be normal. If the veins are not rendered visible by occluding their lower ends, it is possible that they are, in fact, full. The patient should therefore be instructed to sit upright when, unless the venous hypertension is extreme, the top of the column of blood will come into view.

A full and tense external jugular vein on one side only is due to local obstruction and the swelling can often be released by a little rotation of the neck. Attention should be directed to the vein in which the pressure is lowest and where free pulsation is visible. Less commonly the veins on both sides are full and motionless; they may be made to collapse by a change of position or by sitting the patient up. Rarely, in spite of the greatest care, it is impossible to demonstrate the venous pulse.

The jugular pulse consists of three main waves, named by Mackenzie (1902) $a, c$ and $v$, the summits of which are presystolic, systolic and diastolic in time, and two troughs, $x$ and $y$ (Fig. 3). The $a$ wave is due to atrial systole; the $c$ wave, often just a notch on the descending portion of the $a$ wave, is caused by the impact of the underlying 


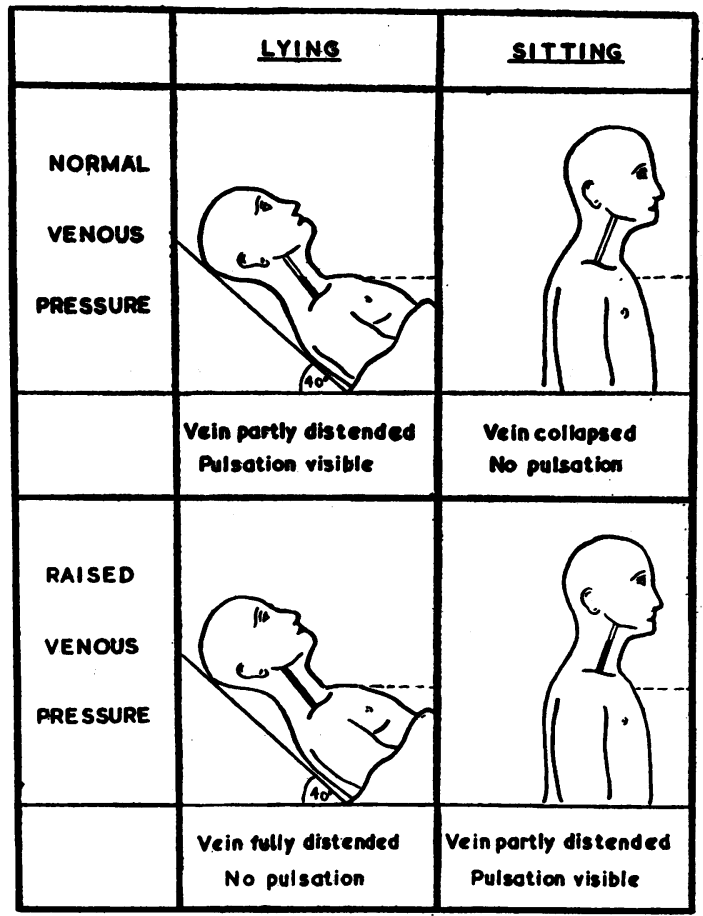

FIG. 2.-The effect of posture on filling and pulsation of the external jugular vein. The broken lines mark the level of the sternal angle (after Lewis).

carotid artery, and the $x$ trough is due to atrial relaxation. The $v$ wave, which appears towards the end of the systole, is due to refilling of the atrium and its peak coincides with the opening of the tricuspid valve. The $y$ trough is caused by the fall in atrial pressure which follows the entry of blood into the ventricle.

Wiggers (I949) studied phlebograms from 800 healthy students and classified them into three groups, which he called the atrial, the modified impact type and the transitional. In the first, which was the most numerous, the $a$ wave was dominant; in the second there was a large $c$ wave, while the third group was intermediate between these two. By inspection it is rarely possible to detect more than two waves, since $a$ and $c$ cannot usually be separated. In a personal series of roo healthy men two waves could generally be seen in the external jugular vein, and in $6_{5}$ of them the larger could be measured and timed; in 47 of these the main wave was atrial.

\section{Differentiation of Venous from Arterial Pulsation}

It is important to be sure that the pulsation which is observed is venous and not arterial. There is no difficulty if the external jugular vein is distended, and the level of filling varies with respira-

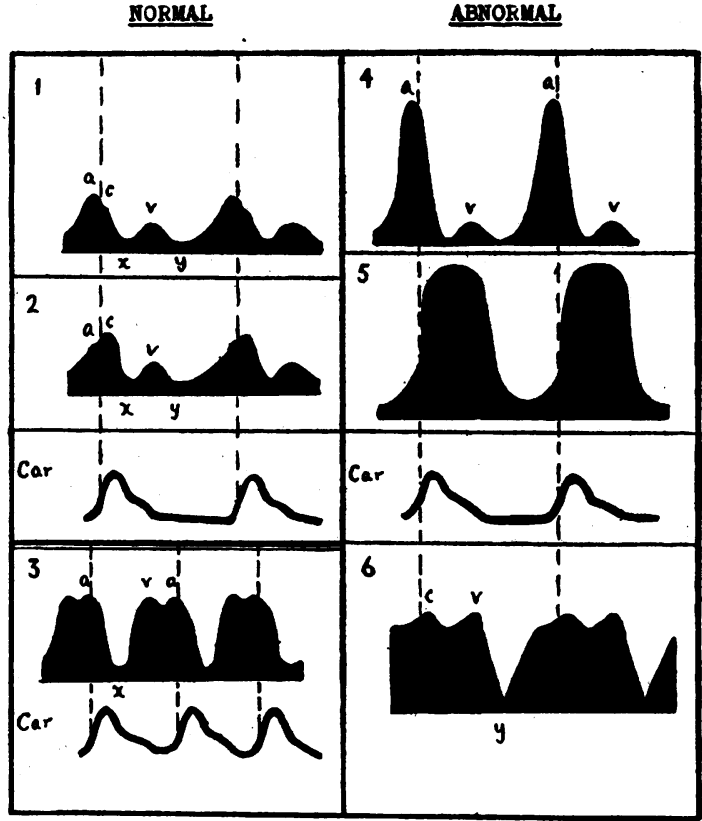

FIg. 3.-Normal and abnormal forms of the jugular pulse:

I. Normal dominant $a$ wave

2. Normal dominant $c$ wave

3. Sinus tachycardia:

summation of $v$ and $a$ waves

4. Giant $a$ wave

5. Ventricular pulse of tricuspid incompetence

6. Exaggerated $y$ descent of constrictive pericarditis

Note.-This figure depicts the rise and fall of blood in the veins, i.e. volume changes. The broken lines indicate the times of the carotid beats.

tion, change of position or abdominal compression; or if there are two waves to every heart beat, or a single wave which is slow rather than sudden and does not synchronize with the carotid pulse. But the distinction is not always easy and venous is often mistaken for arterial pulsation.

Arterial pulsation is usually maximal in the carotid triangle and it increases when the erect posture is assumed. Venous pulsation may also be seen in this situation, but when the patient sits up it falls to a lower level in the neck. Pulsation that is maximal in the subclavian triangles is almost always venous, though the possibility of a kinked carotid must be considered if the pulsation is confined to the right side in a woman. Arterial pulsation that is visible is always readily palpable. Venous pulsation is very rarely strongly palpable and only occasionally can be felt. If the jugular veins are compressed at the root of the neck, venous pulsation ceases above this level, whereas the carotids continue to beat. When the radial pulses are small, striking pulsation in the neck is almost invariably venous. Conversely, if the radial pulses 
are large, striking pulsation in the neck is generally arterial.

When, as during congestion, the venous pulsation tends to lose its undulatory character and becomes more sustained, and sometimes plainly palpable, the direct distinction between it and arterial pulsation may be very difficult; but in such cases the remaining signs of a congested venous system are always apparent.

\section{Measurement of the Jugular Venous Pressure}

The pressure which is recorded in the jugular veins is actually the right atrial pressure and simultaneous measurement of pressures in the right atrium by cardiac catheterization and in the jugular vein by Lewis's method has shown that the two are almost identical.

Pressure must be measured with reference to a fixed point or level. Various reference points have been suggested and there is still no agreement as to which is the best. The ideal reference point would be the centre of the right atrium, but in practice it is impossible to determine this in relation to the surface of the chest; moreover, it varies with respiration and the heart beat. Bloomfield et al. (I946), from a study of lateral chest radiographs, found that the centre of the right atrium in healthy subjects lay on an average 5.8 $\mathrm{cm}$. below the sternal angle. When the heart was enlarged the distance was a little less $(5.6 \mathrm{~cm}$.) and in emphysema a little more $(6.9 \mathrm{~cm}$.). The distance varied with the phase of the respiratory and cardiac cycles and there was also considerable individual variation. Bloomfield et al. concluded that any attempt to predict the position of the centre of the right atrium in relation to the surface of the chest would only be accurate to within 2 or $3 \mathrm{~cm}$.

American and Continental workers commonly take as their zero level a horizontal line $5 \mathrm{~cm}$. below the sternal angle, or $10 \mathrm{~cm}$. anterior to the back when the patient is recumbent, but in England the sternal angle is still the most widely used reference point. As Lewis (I930) showed, it represents approximately the level of normal pressure whether the body is horizontal or vertical or in any intermediate position. Normally all veins lying higher than the sternal angle are collapsed; all lying below it are distended.

The jugular venous pressure is expressed in terms of the vertical distance between the top of the column of blood and the sternal angle during quiet respiration. It is best to record the highest and the lowest points in the cycle; if the excursion is great, this is essential. If the patient cannot lie flat, he should be made to lie as low as he can without distress. If the venous pressure is greatly elevated, he should be propped up in a semi- sitting position so that the top of the venous column lies approximately halfway up the neck.

Borst and Molhuysen (1952) have insisted that a valid venous pressure can be recorded only during inspiration and in the part of the cycle during which the atrial pressure is falling, because then the venous valves are known to be open. This precaution is, however, unnecessary, since there are no competent valves in the superficial jugular veins.

Wood (1956) states that the normal jugular venous pressure ranges between $3 \mathrm{~cm}$. above and $7 \mathrm{~cm}$. below the level of the sternal angle when the patient is horizontal. In a personal series of roo healthy men the venous pressure could be measured in all but one. The average level was $-1 \mathrm{~cm}$. and 93 fell within the range -3 to $+\mathrm{I}$. The pressure was a little lower in summer than in winter. Approximately half the cases were examined during the months May to September and the remainder between October and March. The mean pressure during the warm months was $-1.5 \mathrm{~cm}$. and in the cold months $-0.5 \mathrm{~cm}$. The venous pressure is increased by exercise, but it usually returns to normal or lower within a minute after its cessation (Szekely, I94I). Borst and Molhuysen (1952) observed no measurable change in pressure under the influence of emotion.

It is often stated that pressure over the liver causes a rise of blood in the jugular veins in heart failure, but not in health. This so-called hepatojugular reflux is, in fact, a normal phenomenon and may be produced by pressure on any portion of the abdominal wall (Wood, 1956).

\section{Jugular Venous Hypertension}

A raised pressure in the jugular veins is the earliest evidence of general systemic congestion and precedes signs in the legs or abdomen. Later, if heart failure persists and increases, venous distension will be followed by hepatic engorgement and the appearance of oedema. Similarly, when the heart improves, the venous pressure falls to normal before the oedema disappears.

A raised venous pressure at rest may be found in many conditions besides heart failure. Wood (1956) lists hyperkinetic circulatory states, increased blood volume, bradycardia, increased intrapericardial, intrathoracic or intra-abdominal pressure, partial obstruction of the superior vena cava, tricuspid stenosis and space-filling lesions affecting the right side of the heart. The diseases which cause most difficulty in practice are chronic anaemia, acute nephritis, emphysema and thyrotoxicosis. Congestive heart failure should not be diagnosed in the presence of any of these diseases unless the venous pressure is considerably elevated or the liver is engorged. The possibility of a raised 
venous pressure being due to constrictive clothing or bandages around the waist should not be overlooked.

Persistent jugular venous engorgement without dyspnoea suggests constrictive pericarditis, tricuspid stenosis or superior vena caval obstruction. In superior caval obstruction the liver is not congested. Some jugular pulsation persists while the obstruction is partial, but once it becomes complete all pulsation is lost, anastomotic veins appear over the chest, and the face becomes congested and cyanosed.

\section{Abnormal Jugular Pulsation}

The commonest and most important abnormality in the form of the venous pulse is an exaggeration of the normal $a$ wave (Fig. 3 ). The peak of this wave rises until in extreme instances its amplitude may exceed $10 \mathrm{~cm}$. It is best seen with the patient sitting upright and usually increases during inspiration. In the internal jugular vein its abrupt rise and fall resembles the carotid pulsation of aortic incompetence, for which it is sometimes mistaken. The $a$ wave can be distinguished by the fact that the carotid pulse is small and follows the onset of the venous wave. Sometimes sudden systolic collapse of the vein is more striking than its protrusion.

Laubry and Pezzi (1913) first described a large $a$ wave as a sign of congenital pulmonary stenosis; and Abrahams and Wood (195I) showed that the size of this wave broadly reflects the degree of right ventricular hypertension in this disease. An exaggerated $a$ wave is also found in pulmonary hypertension and in tricuspid stenosis. The $a$ wave is not always abnormally large in pulmonary stenosis or hypertension, but, provided the patient is in sinus rhythm, it is invariably the dominant wave. It declines in right heart failure and disappears with the onset of auricular fibrillation.

Another common and important abnormality of the venous pulse is the ventricular form due to tricuspid incompetence (Fig. 3). At the onset of ventricular systole, blood regurgitates into the right atrium and the caval veins and the distension of the jugular veins is maintained until the ventricle relaxes. This pansystolic or $c v$ wave is even more striking than the exaggerated $a$ wave because of the great distension of all the jugular veins which occurs with every heart beat. The start of the $c v$ wave is a little later than that of the $a$, synchronizing with the carotid impulse; it is more sustained and it persists in auricular fibrillation. The $c v$ wave does not necessarily indicate organic tricuspid disease; the incompetence is more often temporary and due to dilatation of the tricuspid valve ring resulting from right ventricular failure. When failure subsides the competence of the valve returns and the abnormal wave disappears. The earliest sign of tricuspid incompetence is premature appearance of the $v$ wave from accelerated filling of the right atrium (Mackenzie, 1902).

Another striking and important abnormality of the jugular pulse is that described by Friedreich (I866) in constrictive pericarditis (Fig. 3). The main feature of this pulse is a steep dip in diastole, an exaggeration of the normal $y$ descent. This recession, which is immediately preceded by a similar recession in the right ventricular pressure curve, has been shown to be due to a high-pressure gradient between the right auricle and ventricle (Mounsey, 1955). Although characteristic of constrictive pericarditis, it is not pathognomonic of it, and it may be found in other conditions, such as cardiac myopathy, in which there is an unusually high venous filling pressure.

In the diagnosis of arrhythmias the electrocardiogram is unrivalled. There are, however, emergencies when this instrument is not available, and then inspection of the venous pulse may provide valuable information. It is frequently possible to distinguish complete heart block from sinus bradycardia by observing the position of the $a$ wave in the cardiac cycle. In sinus bradycardia it precedes the carotid impulse, as in health, whereas in complete heart block its position is continually changing and periodically, when atrial and ventricular systole coincide, a wave of exceptional amplitude (the so-called cannon wave) appears. The jugular pulse may likewise enable auricular flutter to be differentiated from fibrillation. In flutter, rapid regular $a$ waves are seen, but in fibrillation these are absent.

\section{Conclusion}

Inspection of the jugular veins deserves to take its place beside palpation of the radial artery in the clinical examination of a patient suspected of cardiovascular disease. The one procedure is as simple as the other and yields information of equal if not greater value. It tells at once whether oedema is due to heart failure and when congestive failure has developed provides an accurate index of its progress. It gives warning of overloading of the circulation during intravenous infusion or treatment with salt-retaining hormones and provides a vital clue to the diagnosis of pulmonary hypertension, pulmonary stenosis, tricuspid valve disease, constrictive pericarditis and superior vena caval obstruction.

\section{Acknowledgments}

I am indebted to Dr. William Evans, Dr. Evan Bedford and Professor Kekwick for a number of valuable suggestions and to Dr. Russell Bearn for advice on the anatomical details.

Bibliography continued on next page 


\section{BIBLIOGRAPHY}

ABRAHAMS, D. G., and WOOD, P. (195I), Brit. Heart F., 13, 519. BLOOMFIELD, R. A., LAUSON, H. D., COURNAND, A., BREED, E.'S., and RICHARDS, D. W., jun. (1946), $\mathcal{F}$. clin. Invest., 25, 639 .

BORST, J. G. G., and MOLHUYSEN, J. A. (1952), Lancet, ii, 304 FRIEDREICH, N. (1866), Dtsch. Arch. klin. Med., I, 241.

HALES, S. (1733) 'Statical Essays. Containing Haemastaticks: or, an account of some Hydraulic and Hydrostatical Experiments, made on the Blood and Blood-Vessels of Animals. W. Innys and R. Manby, London.

KEITH, A. (1 g08), $\dot{f}$. Anat. and Physiol., 42, I.

LAUBRY, CH., and PEZZI, C. (1913), Arch. Mal. Coeur, 6, 433.

LANCISI, G. M. (1728), 'De Motu Cordis et Aneurysmatibus,' Rome.

LEWIS, T. (1930), Brit. med. f., i, 849.
LEWIS, T. (1948), ' Diseases of the Heart,' Macmillan \& Co. Ltd., London, 4th Edition.

MACKENZIE, J. (1893), 7 . Path. Bact., 2, 84 and 273.

MACKENZIE, J. (I9O2), 'The Study of the Pulse,' Young J. Pentland, Edinburgh and London.

MORITZ, F., and VON TABORA, D. (1910), Dtsch. Arch. klin. Med., 98,475 .

MOUNSEY, J. P. D. (1955), Brit. Heart F., 17, 143.

POTAIN, P. C. E. (1867), Bul. Soc. Méd. Paris, 4,3

SZEKELY, P. (I94I), Amer. Heart F., 22, 360.

WIGGERS, C. J. (1928), "The Pressure Pulses in the Cardiovascular System,' Longmans Green \& Co., London.

WIGGERS, C. J.' (I949), 'Physiology in Health and Disease,' Henry Kimpton, London, 5 th Edition, p. 685

WOOD, P. (1950), Brit. Med. F., 2, 639 and 693.

WOOD, P. (I956), 'Diseases of the Heart and Circulation,' Eyre and Spottiswoode, London.

Bibliography continued from page 382: Surgical Endocrine Ablation for Advanced Breast Cancer

LUFT, R. (1957) Edinburgh University Lecture.

LUFT, R., and OLIVECRONA, H. (1953), $\mathcal{F}$. Neurosurg., 10, 301

LUFT, R., OLIVECRONA, H., and SJORGEN, B. (1952) Nord. med., $47,35 \mathrm{I}$.

LUFT, R., OLIVECRONȦ, H., IKKOS, D., NILSSON, L. B. and LJUNGGREN, H. (1956), Amer. F. Med., 21, 728

MALLARD, J. R., MCKINNELL, A., and FRANCOIS, P. E. (1956), Nature, 178, 1240.

MATSON, D. D. (I 956), Symposium on Hypophysectomy, SloanKettering Insitute. To be published.

MCKENZIE, A. (1955), Lancet, ii, I 129.

NATHANSÖ, I. R., RICE, C., and MEIGS, J. V. (1940), Amer. F. Obstet. Gynec., 40, 936 .

NICKSON, J. J. (I956), Symposium on Hypophysectomy, SloanKettering Institute. To be published.

NORTHFIELD, D. W. C. (1949), Proc. roy. Soc. Med., 42, 845.

NORTHFIELD, D. W. C. (1957), Discussion Roy. Soc. Med., March, 1957.

NOT'TER, G. (1957), Personal communication.

PATTISON, A. R. D., and SWAN, W. G. A. ( 1938 ), Lanct $t$, i, 1265.

PEARSON, O. H. (1956), Proceedings of the Fourth Conference in Steroid Hormones and Mammary Cancer, Council on Pharmacy and Chemistry, 1956.

PEARSON, O. H. RAY, B. S. WEST, C. D., HAROLD, C. C., MACLEAN, J. P., and LI, M. C. (I 954), 7. clir. Invest., 33, 956.

PEARSON, O. H, WEST, C. D., LI, M. C., MACLEAN, J. P., and TREVES, N. (1955a), A.M.A. Arch. Int. Med., 95, 357.

PEARSON, O. H. WEST, C. D., MACLEAN, J. P., LI, M. C., and LIPSETT, M. B. (1955b), Amer. Surgeon, 21, 1075.
PEARSON, O $\mathrm{H}$, RAY, B. S HAROLD C. C. LI, M. C., MACLEAN, J. P., and LIPSETT M. B. (r956), 买.A.M.A.,

PERLIA, I C. P., KOFMAN, S., NAGAMANI, D., and TAYLOR, S. G. (I956), Ann. Int. Med., 45, 989 .

RADLEY SMITH, E. I. (1957), Discussion Roy. Soc. Med.. I957. Surgical Forum, r952. Philadelphia, W. B. Saunders Co., 1953, p. $68 \mathrm{I}$.

RAY ${ }^{1953}$ B. P. (1956), Symposium on Hypophysectomy, SloanKettering Institute. To be published.

ROTH, M. (1889), Cor-Bl.f. schweitz. Aertze., 19, 146. (Cited by Falls, 1955.)

ROTHENBERG, S. F., JAFFE, H. L., PUTNAM, T. J., and SIMKIN, B. (I955), A.M.A. Arch. Neurol. Psych., 73, 193

RUSSELL, D. S. (1956), Lancet. i, 466.

SHEEHAN, H. L., and SUMMERS, V. K (1949) Quart. F. Med.,

S'TRONG, 3.9 J. A , BROWN, J. B., BRUCE, J., DOUGLAS, M., KLOPPER, A. I., and LORAINE, J. A. (I956), Lancet, ii, 955 .

TAYLOR, S. G , LI, M. C., ECKLES, N., SLAUGHTER, D. P., and MCDONALD, J. H. (1953). Cancer, 6, 997

TREVES N (1956), Proceedings of the Fourth Conference in Steroid Hormones and Mammary Cancer, Council on Pharmacy and Chemistry, I056.

WEST, C. D., HOLLANDER, V. P., WHITMORE, W. F., RANDALI, H. T., and PEARSON, O. H. (I952), Cancer, 5,

YUHL E. T. HARPER, P. V., RASMUSSEN, T., and BERGENSTAL, D. M , Surgical Forum, r955, Chicago, W. B Saunders Co.. 1956, p. 489

References from page 388: Anticoagulants in Reconstructive Surgery

\section{REFERENCES}

I. DEGNI, M., and LANFRANCHI, W. (1954), Heparinizacao Regional: 'Vantagens o Desvantagens-Anais do Segundo Congresso Latino-Americano de Angiologia.

2. FREEMAN, L. E., WYLIE, E. J., and GILFILLAN, R. (I950), 'Regional Heparinization in Vascular Surgery,' Surg. Gynec. Obst., 90, 406, 412.

3. FREEMAN, N, E., and GILFILLAN, R. (1952), 'Regional Heparinization after Thromboendarterectomy in the Treatment of Obliterative Arterial Disease,' Surgery, 31, 1 I 5.
4. MURRAY, D. W., and BEST (1938), 'Use of Heparin in Thrombosis,' Ann. Surg., 108, $163,177$.

5. MURRAY, D. W., GORDON, and JAMES, J. M. (1940), 'Prevention of Acute Failure of Circulation Following Injuries to Large Arteries,' Brit. med. F., ii, 6, 7.

6. WYLIE, E. J., GARDNER, R., JOHANSEN, R:, and McCORKLE, H. (I950), 'An Experiment of Regional Heparinization,' Surgery, 28, 29, 35 .

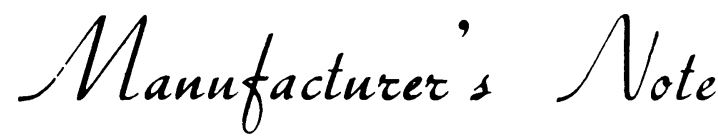

\section{SUMMER EXHIBITION}

\section{July II to August 23, 1957}

Although the Ilford Department of Radiography and Medical Photography is well known as a place of interest to the many visitors who enter its doors, this year a special effort is being made to add to its technical appeal by holding a summer exhibition.

The exhibition will include many attractive features embracing a wide range of radiographs of technical and diagnostic interest, practical demonstrations of some of the more unusual technical procedures and items of special photographic appeal.

Well-known members of the technical staff will be available for discussions and for the special demonstration features.

The exhibition, to be held at Tavistock House North, Tavistock Square, will be for all users of $\mathrm{X}$-ray and photographic materials and visitors can anticipate a cordial welcome. 